\title{
Effects of HOTS-based Module Approach on Pupil's Errors in the Topic of Measurement and Geometry in Urban and Rural Schools
}

\author{
Noorashikim Noor Ibrahim ${ }^{1}$, Ahmad Fauzi Mohd Ayub ${ }^{1,2, *}$, Aida Suraya Md. Yunus ${ }^{1,2}$ \\ , Kathiresan Gopal ${ }^{1}$, Nur Raidah Salim ${ }^{1}$ \\ ${ }^{1}$ Institute for Mathematical Research, Universiti Putra Malaysia, 43400 UPM Serdang, Malaysia \\ ${ }^{2}$ Faculty of Educational Studies, Universiti Putra Malaysia, 43400 UPM Serdang, Malaysia
}

Received July 16, 2019; Revised September 16, 2019; Accepted September 23, 2019

Copyright (C) 2019 by authors, all rights reserved. Authors agree that this article remains permanently open access under the terms of the Creative Commons Attribution License 4.0 International License

\begin{abstract}
This study was to investigate the effect of HOTS-based module approach on pupil's error in the topic of measurement and geometry year five. For the purpose of the study, a quasi- experimental research was conducted on two intact groups. It was conducted in two schools (Schooll and School2) located in urban area and two schools (School3 and School4) located in rural area in one of the states in Malaysia. Sample in urban schools was a total of 40 pupils (20 pupils in the treatment group and 20 pupils in the control group) while, for rural schools, 37 pupils (19 pupils in the treatment group and 18 pupils in the control group) participated in this study. The data collection instrument used in this study was the four item problem-solving test on the topic of Measurement and Geometry developed by the researcher. Fong's Schematic Model was used to analyse levels of errors in solving word problem. The analysis of the result from the test showed that pupils in treatment groups in both schools made less errors compared with pupils in control group. This result indicated that pupils who used HOT-based module committed less errors in solving Measurement and Geometry problems.
\end{abstract}

Keywords Higher Order Thinking Skills, Errors, Measurement and Geometry

\section{Introduction}

One of the important skills in the $21^{\text {st }}$ century is Higher Order Thinking (HOT) which is acknowledged as accelerative skills in this changing era. Individual needs to be not only educated but also hold the important ability; being able to think effectively and to make right decisions as well as creative in many way, in order to live well or even merely exist in this highly competitive world [1]. According to Richland and
Simms [2], it means that, education in the 21st century should highlight students' skills for HOT, transfer, and flexible reasoning over memorizing of facts. Thomas and Thorne [3] suggest that HOT is thinking skill that is above the level of memorizing facts or giving back the memorized fact to someone, in the same way it was read or told while, Brookhart [4] identifies of HOT as three categories which were transfer, critical thinking, and problem solving.

\subsection{Teaching Higher Order Thinking}

As we all know, Bloom's Taxonomy [5] is not the only framework for teaching thinking, but it is the best commonly used. Instead of teaching students to recall facts Bloom's objective was to support higher forms of thinking in education, such as analysing and evaluating. According to Huitt [6], the cognitive domain comprises of abilities and skills within stated in six groups which are knowledge, comprehension, application, analysis, evaluation and synthesis. Each of the behaviour needs to be learned before the next one can take place. Teacher should use this useful information in planning their lesson. Anderson and Krathwothl [7], have revised Bloom's taxonomy in order to adequately cover the more outcome-focused modern education objectives. This was done by changing the names of the groups from nouns to active verbs. They also had inverted the order of the highest two groups; and slightly rearranged them so they became like in Figure 1.

In this study, the researcher utilized the revised Taxonomy Bloom as a framework in developing HOTS-based module in order to infuse HOTS within the content knowledge. The revised Taxonomy Bloom which is explicitly structured was able to assist teachers in the teaching and learning process. Furthermore, it is widely used in the new curriculum of primary schools. Studies that are related to HOTS had been done worldwide. This section indicates few studies related to HOTS. Sulaiman, Ayub and Sulaiman [8] had revised studies on curricu- 


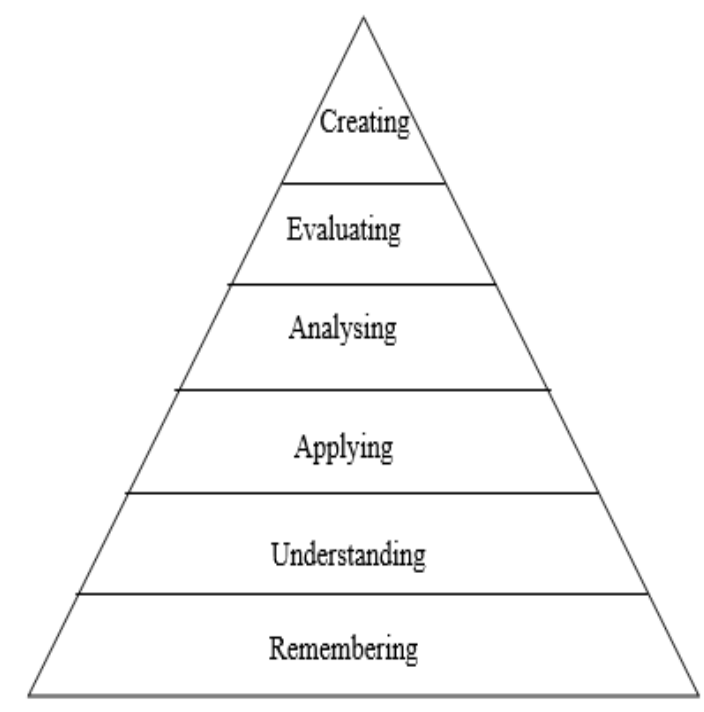

Figure 1. Revised Taxonomy Bloom (Source: Adopted from http://iacbe.org/oa-blooms-taxonomy.asp).

lum changes in Malaysian primary schools which HOTS and standard-based assessments were given. They stated that in order to enhance pupils' HOTS, changes should be made in curriculum content, teaching strategies or assessment challenge. Richland and Simms [2] reviewed collected studies on analogy and disciplinary of HOT. From their analysis, they recommended that relational reasoning could be effectively considered in the cognitive behind HOT.

The most significant task in higher education today, is to cultivate its students to be competitive. Teachers were asked to emphasize thinking skill in the teaching processes so that it can be applied from classroom situation to a variety of real-life context. Surya and Syahputra [9], conduct a study that aims to improve the ability of high-level thinking by developing learning models based on mathematics problems for 11th grade students in North Sumatra. The result showed a significant improvement of student's problem solving ability. In this study, active interaction in the problem based learning had influence in learning and improves students understanding of mathematics concepts in real life which indirectly improved the ability of HOTS among students. Leung [10] conducted a survey research to 41 secondary school teachers in order to compare the teaching processes and strategies for cultivation students' HOT. The finding has shown a strong influence towards examinationoriented learning. The more experienced ones further agree that examination-oriented strategies were aligned with the development of HOT. Pegg [11] studied the causes for the problems and challenges that primary and secondary teachers had to face in order to encourage higher order understandings in their students. The findings showed that activities of instruction and assessment need to be closely intertwined by organizing environments for HOTS activities at the suitable times, within the syllabus content which covered in class. He also recommended that teachers should provide students with non-routine questions in order to achieve HOTS as; in general, these questions require at least relational responses. As a conclusion, in order to infuse HOTS in the curriculum, changes in instructions and assessment should be made. Solving non-routine problems which exposed student to the real-life context should be emphasized in the teaching and learning process.

\subsection{Errors in Mathematics}

The objective of the KSSR for Mathematics is to build students' understanding of number concepts, basic skills in calculation, easy to understand mathematical ideas and to increase students' competent to apply mathematical knowledge and skills effectively and responsibly in everyday life [12]. In order to design and develop learning settings that support understanding efficiently, teachers need to be aware of students' difficulties in learning mathematics [13]. Pupils with mathematics difficulties were at risk of facing persistent failure, commited errors illustrate their individual difficulties, for instance they failed to understand certain concepts, techniques, problems [14]. Even though errors and misconceptions are related, they are different. An error is a mistake, slip, faults or incorrectness and a deviation from correctness. According to Riccomini [15], random errors are accidental, non-recurring wrong answers which learners can readily correct by themselves. Hansen et al. [16], stated that an error could be created for many reasons. For example, the result of carelessness, misinterpretation of symbols or text, lack of relevant experience or knowledge related to that mathematical topic, learning objective and concept, or a lack of awareness or inability to check the answer given. An error might be caused due to a misconception [16].

\subsection{Error Analysis in Mathematics}

Previous studies on error analysis indicated that error analysis is focused on computational tasks and word problems. Among the studies in computational tasks are Robert [17], who classified four major categories of failure strategies which are wrong operation, clear computation error, faulty algorithm and random responses. Engelhardt [18] identified nine types of errors in computational which are basic facts, faulty algorithm, incomplete algorithm, incorrect operation, inappropriate operation, inappropriate inversion, grouping, identity and zero errors. While, Spiers [19] mentioned that children who always make the same types of errors were probably not due to their carelessness but the reflection of their cognitive styles or their stage of development. One of the most common mathematics difficulties is the difficulties in word problems [20,21]. Among studies conducted on the word problems in the form of written tasks are Newman [22], Clement [23], Clarkson [24], and Watson [25]. Both computational tasks and word problems are significant in mathematics education due to their useful information for effective teaching and learning. They not only point out the errors, but also recommend to us that what we teach may lead to students' errors [26]. Radatz [27] proposed the process of classifying errors as (a) language difficulties, (b) difficulties in obtaining spatial information, (c) poor mastery of prerequisite facts and concepts, (d) incorrect links or inflexibility of thinking and (e) application of irrelevant rules or strategies.

According to Fong [28], schema contains interconnected 
network between different sets of knowledge that make up the concept. Schematic model for error analysis is constructed on the schematic approach for analysing students' strategies in solving both computational task and word problems. Fong [28] then, summarised various types of error into a network of categorical of errors. The network consists of four groups of knowledge which are language, mathematics themes, operational and psychological factors. Figure 2.0 shows that reading ability and comprehension are listed under language. Students with inability to read and/or understand word problem are considered under this category. An operational knowledge is divided into two categories which are external and internal knowledge. Encoding is under external knowledge that concerned with different types of information, for example verbal statements (words), symbols, and spatial figures. While the internal knowledge category is consist of the process such as transformation, recalling, relating computation and application of information are stated under. These processes are activated within short-term memory. Under the mathematical themes, the knowledge of basic facts, algorithms, and concepts are listed. Finally, the psychological factors include motivation and carelessness in student's written work. After conducting a study on analysing errors in the topic of ratio and proportions, Fong proposed categorical errors that classified in terms of pupils' schematic knowledge. These categories are (1) no solution, (2) using irrelevant procedure, (3) incomplete schema with no errors, (4) incomplete schema with errors and (5) complete schema with errors. Further then, Fong conceptualized two levels of errors in solving word problems.

Figure 3 summarized the relationship of two levels of errors into a network of errors. Fong's model emphasizes the significant of schematic knowledge to mathematical problem solving. He pointed out that a pupil must first overcome the first level of errors in order to successfully solve problems. In this study, the researcher utilized Fong's model of schematic knowledge since the model include both computational task and word problem that is suitable for this study on written tasks.

Various studies have been conducted in analysing errors around the world. Radatz [14] claimed that by analysing the student's error, we will understand the process of faulty problem solving, hence it also provides us with information on the attitudes toward mathematical problems. Therefore, error analysis gains significance in two respects which are the requirements of academic practice and research strategy for clarifying some basic questions of mathematics learning. The analysis of errors establishes an important source for teachers [29]. Errors disclose the type of understanding used by the student when establishing the answer to the question given [30]. Thus, analysis of errors is suitable as a critical indication for teachers in understanding the knowledge used by the students in an activity. Bastien and Bastien-Toniazzo [31] as cited in [30] indicate that students may give some wrong answers even when they used the right knowledge (often, student used an erroneous perspective due to the structure of the question). They can provide some incorrect answers but they follow different ways of thinking and, at the end they proposed correct answer that came out from the incorrect knowledge. These wrong answers are expressively given by the student after they realize that there is other option to take. Indeed, the number and types of errors can be an important source of information for teachers $[32,33]$.

Jiang [26] conducted a study of comparison between student in Singapore and students in Mainland China on analysing errors in solving word problems on the topic of Speed. The researcher used Fong's schematic model to analyse errors made by 1002 Singapore and 1070 Chinese students in grades 6-8. The result showed that the students from both countries failed to get correct answers to the problems. They often made E3 (incomplete schema with errors), E4 (using irrelevant procedures), and E5 (no solution) types of errors in the first level. Whereas, the second level error analysis showed several similarities between the Chinese and the Singapore students in making errors in computations, misunderstanding of the problems, mismatching of distances and speeds in finding times, and misconception of average speed.

Maf'ulah, Juniati and Siswono [34] conducted a qualitative with descriptive approach study to identify the elementary school pupils' error in solving arithmetic problem which is related to the reversibility concept. The sample involved was 96 pupils of the 5th grade in Jombang, Indonesia. The result of the study indicated that there are still many elementary school pupils who experience such difficulties in solving arithmetic problem related to their reversibility. The researchers suggested that the elementary school teacher should draft up a solution to minimize the errors which are committed by the pupils in solving the certain arithmetic problems later. Salleh et al. [35] conducted a study to examine the types of systematic errors and error patterns that are commonly made by students in the addition and subtraction operation of fractions. The sample involved in this study is 120 year five pupils in Besut, Terengganu. The result of the study showed that for the operation of addition of fractions, $50.4 \%$ consisted of a systematic error, random error (13.1\%), and careless error $(7.7 \%)$. While for the operation of subtraction of fraction, $56.1 \%$ consisted of systematic errors, $16.3 \%$ random errors and $3.9 \%$ careless error. The researchers suggested that teachers should use various teaching approaches based on pupils' ability in order to minimize the error committed by the pupils. Remedial action should be conducted immediately, not to burden teachers and pupils, but to ensure the objective of teaching and learning is fulfilled.

Herholdt and Sapire [30] piloted a study of errors in students' work with the purpose to look for possible explanation for the errors. The sample was pupils of grade 1 to 4 in South Africa. The findings show that a lot of errors committed by pupils in both the control and intervention groups were common errors. The majority of the errors were of conceptual nature, although lot of procedural errors was also noted. The researchers also highlight that it is important that teachers are aware of these errors and misconceptions, and know how to address them. As a conclusion, errors committed in solving mathematics problems can be utilized to develop HOTS among pupils. Errors committed by the pupils indicated that how much understanding of knowledge and skills are needed to enhance HOTS through mathematics content. Teachers should use various approaches in order to minimize the error made by the pupils. 


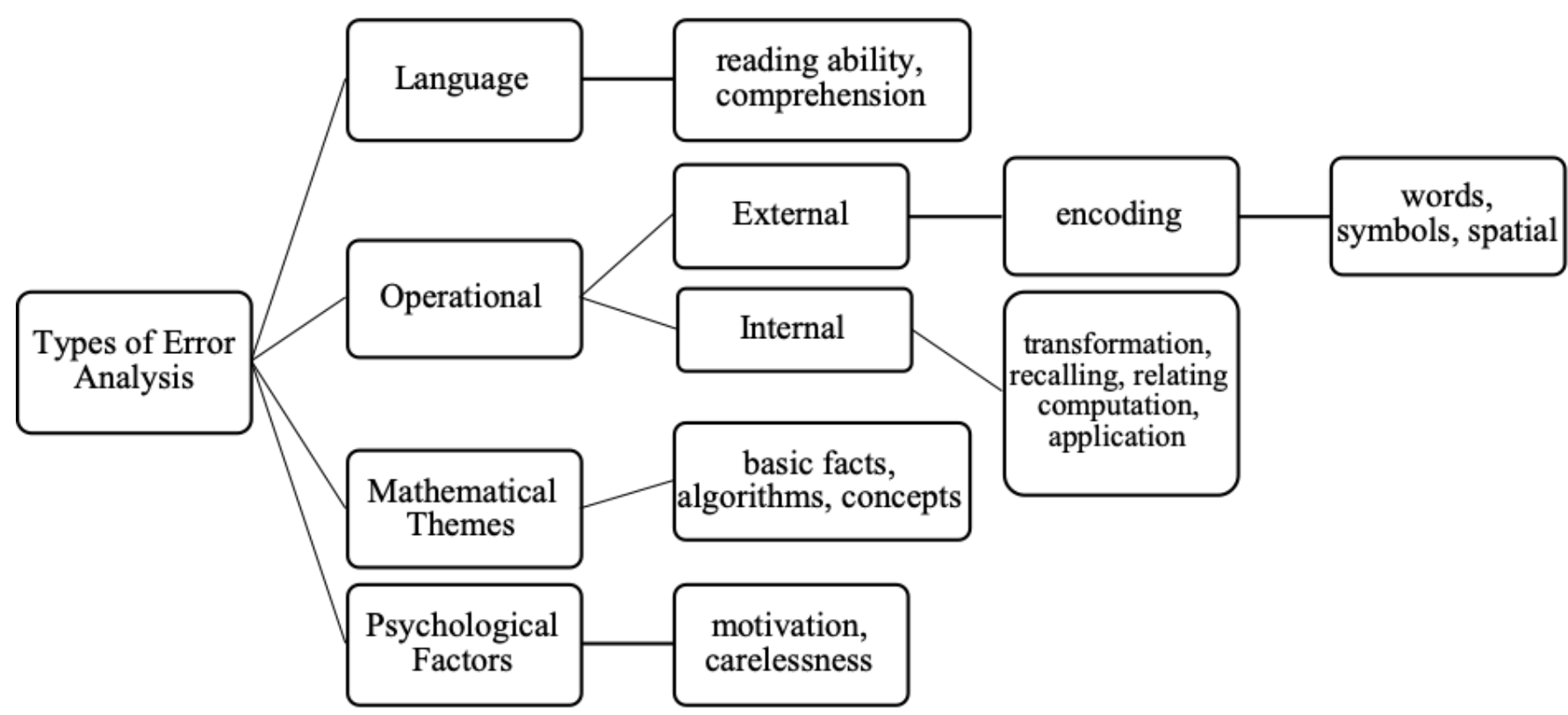

Figure 2. Summary of the Types of Errors on Error Analysis.

\section{Level 1}

(Schematic Errors)
Level 2

(Categorical Errors in Terms of Knowledge)

\section{Complete schema with errors}

2. Incomplete schema with no errors

3. Incomplete schema with errors

4. Using irrelevant procedures

\section{Language}

2. Operational

3. Mathematical Thematic

4. Psychological

5. No Solution

Figure 3. A Network of Two Levels of Errors of Problem Solving.

\section{Research Objective}

The research objective for this study is to compare the categories of error and misconceptions among year five pupils' between urban and rural schools in the topic of Measurement and Geometry.

\section{Methodology}

\subsection{Research Design}

In education, many experimental situations occur in which researcher need to use intact groups. This might happen because of the availability of the participants or because the setting prohibits forming artificial groups [36]. This study will use the quasi-experimental research design by using the existing class of year five pupils, designating one as the experimental 
group and one as the control group. Randomly assigning students to both groups will disrupt classroom learning. The research design is the pretest-posttest control group design. Figure 4 shows the research design model which is used in this study.

Sampling procedures refers to the process of selecting the individuals [37]. Kelantan is divided into ten districts. There are a total of 418 primary schools in Kelantan. Kota Bharu has the largest number of primary schools in the state of Kelantan. There are 96 primary schools in Kota Bharu. In this study, four national schools were selected since national schools type was the majority schools in the district of Kota Bharu. These schools were with the average academic achievement (band 3, 4, and 5). The samples were selected using simple random sampling technique for selecting the schools, selecting two classes from each school and selecting experimental groups from each class since it is easy and obtains accurate representation of a larger population. Manual lottery method was used where each school was assigned a number and, two numbers were drawn. Next, numbered classes involved (two classes with highest achievers and lowest achievers were excluded) in each selected schools. Again, two numbers represent classes were drawn from each school, and subsequently, the numbered class was chosen to determine groups for treatment and control. Four schools were selected in this study. Two schools (School1 and School2) located in urban area and two schools (School3 and School4) located in rural area in one of the states in Malaysia. Sample in urban schools was a total of 40 pupils (20 pupils in the treatment group and 20 pupils in the control group) while, for rural schools, 37 pupils (19 pupils in the treatment group and 18 pupils in the control group) participated in this study.

\subsection{Threats to Experimental Validity}

It is important to use a quality instruments, so that the researcher can make conclusion based on the information obtain from these instruments. Therefore, researcher uses a number of procedures to make sure that the inferences they produce are valid and reliable. Both internal and external validity are concerned threat in this study (Ary, Jacob, Sorensen \& Walker [38]). According to Freankel, Wallen, and Hyun [37], validity is defined as appropriateness, meaningfulness, correctness, and usefulness of inferences that the researcher makes. Internal validity refers to the inferences whether the changes in dependent variables, in facts caused by independent variables in a particular research rather than the extraneous factors [38, 39]. As this study is a quasi-experimental, some treats to validity may affect the outcomes of the study. This study has taken some measures to control for both internal and external validity as described in the following subsections.

\subsubsection{Internal Validity}

\section{History}

History refers to an event occurs between the pre-test and post-test that affects one group more than the other group [40]. This kind of threats usually occurs when the time between conducting treatments and doing measurements is too long. In educational experiments, it is impossible to have tightly controlled environment and monitor all events. However, the researcher can have the control and experimental groups experience the same activities (except for the treatment) during the experiment [41]. In this study, in order to control this treat, the intervals between data collection sessions are kept short. In addition, the control group was measured at exactly the same duration points (after 12 weeks) in the research design.

\section{Maturation}

Gay, Mills and Airasian [42] referred natural physical, intellectual, and emotional changes that occur in the subjects over a period as maturation. Maturation threat exist if participants in one group become more experienced, tired, or bored than participants in the other group [40]. The best way to control for maturation is to include a well selected comparison group in the study [37]. In this study, the participants are selected from the same age with the similar level of knowledge as same background as possible. There are two groups involved in the experiment which are the control group and the experimental group. In order to control the changes which may occur to the participants during the experiment, the duration between pre-test and post- test is 12 weeks and between post-test and post-delayed test is two weeks which is not too long to cause maturation threat.

\section{Statistical Regression}

According to Freankel, Wallen and Hyun [37], a regression threat may be present whenever change is studied in group that is extremely low or high in its pre-intervention performance. In this study, the researcher tries not to select students' with extremely low or high scores for the sampling, so it does not tend any regression to the mean of re-testing. The pre-test was conducted to both groups and it also was used as a covariate in the data analysis.

\section{Different Selection of Subjects}

As mention earlier, this study went through three levels (locations, schools and groups) of randomize selection using simple random sampling technique. However, it was difficult to select random sample of students in the experiment groups. Since this study includes intact groups, differential selection posed a threat to internal validity. Firstly, classes that were randomly chosen in this study were based on school reports and discussions with the school's headmaster and mathematics teachers in which both groups. The controlled and treatment group had comparable socio-economic and ethnic background, and each class was homogenous in ability. Secondly, the mid-examination scores were selected for both groups for the group initial equivalence. Finally, the subjects' profile information, such as students attending mathematics tuition for both groups were collected to ensure that the groups were similar traits were used in this study. Running an ANCOVA would also remove the variation in the experimental and control group that is due to extraneous variables.

5. Different Selection of Subjects Experimental Mortality or 


\begin{tabular}{clllcll} 
& School1 & HOTS-based module & $\mathrm{O}_{1}$ & $\mathrm{X}_{1}$ & $\mathrm{O}_{2}$ & $\mathrm{O}_{3}$ \\
& & Control group & $\mathrm{O}_{1}$ & & $\mathrm{O}_{2}$ & $\mathrm{O}_{3}$ \\
\cline { 2 - 7 } Urban & School2 & HOTS-based module & $\mathrm{O}_{1}$ & $\mathrm{X}_{2}$ & $\mathrm{O}_{2}$ & $\mathrm{O}_{3}$ \\
& Control group & $\mathrm{O}_{1}$ & & $\mathrm{O}_{2}$ & $\mathrm{O}_{3}$ \\
\hline \multirow{4}{*}{ Rural } & School3 & HOTS-based module & $\mathrm{O}_{1}$ & $\mathrm{X}_{1}$ & $\mathrm{O}_{2}$ & $\mathrm{O}_{3}$ \\
& & Control group & $\mathrm{O}_{1}$ & & $\mathrm{O}_{2}$ & $\mathrm{O}_{3}$ \\
\cline { 2 - 7 } & School4 & HOTS-based module & $\mathrm{O}_{1}$ & $\mathrm{X}_{2}$ & $\mathrm{O}_{2}$ & $\mathrm{O}_{3}$ \\
& & Control group & $\mathrm{O}_{1}$ & & $\mathrm{O}_{2}$ & $\mathrm{O}_{3}$ \\
\hline
\end{tabular}

$\mathrm{X}_{1}$ : Treatment group School1 $\quad \mathrm{O}_{1}$ : Pre-Test

$\mathrm{X}_{2}$ : Treatment group School2 $\quad \mathrm{O}_{2}$ : Post-Test

$\mathrm{O}_{3}$ : Delayed-Post Test

Figure 4. Research Design Model

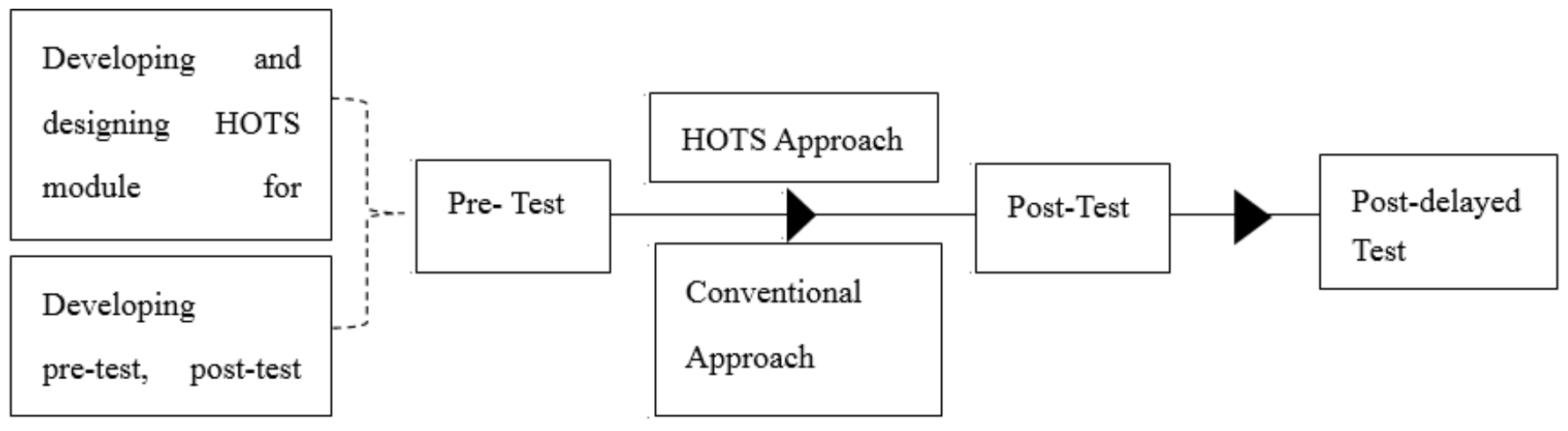

Figure 5. Representation of the Research Experiment 


\section{Attrition}

Mortality or attrition threat exists if the dropping out of participants from either group produces group differences on the post-test scores [40]. In this study, due to the existence of intact groups and as the students in the classes had to be in the class and there is no choice for them, there is no attrition during the study. In this case, mortality is not considered as a threat in internal validity.

\section{Testing}

Testing threat exists if one group of participants reacts differently to taking the pre-test [40]. Participants may become familiar with the outcome measures and remember responses for later testing. During some experiments, the outcome is measured more than one time, such as in pre-test. To remedy this situation, experimental researchers measure the outcome less frequently and use different items on the post-test than those used during earlier testing [41]. To control this threat, the researcher used the test which is not identical but similar in the nature of questions. The duration between the pre-test and post-test is 12 weeks while post-test and post-delayed test is 2 weeks.

\section{Measuring instruments}

Instrumentation threat exists if the nature of the dependent variable or the way it is measured varies across the nonequivalent groups [40]. Gay and Airasian [42] stated that the instrumentation threat refers to the unreliability or lack of consistency in measuring or calibrating instruments that can result in an invalid assessment performance. In this study, first, the research procedure will be standardized for both groups before experiments. Second, the same observation scales were implemented for all observations and monitored the procedure and activities. Third the validity and reliability of the instruments and module had been checked by the panel of experts.

\section{Selection-Maturation Interaction}

Several of the threats mentioned thus far can interact (or relate) with the selection of participants to add additional threats to an experiment. Individuals selected may mature at different rates [41]. According to Ary et al. [38], this threat may occur especially in the study of experimental design where both groups (the experimental and control groups) are not randomly selected; instead they are pre-existing intact groups. The mid-year examination and grades in mathematics subject were analysed to check on similarity of the groups. The students' profiles information was also considered. Both groups were taught by a group of teachers and they had an identical setting in terms of the lesson structure, mathematical tasks, and contact hours. Thus, the selectionmaturation interaction would not be a threat to internal validity.

\section{Implementation}

According to Freankel, Wallen, and Hyun [37], the treatment or method in any experimental study must be administered by someone who involved in the study, such as the researcher, the teachers, or some other person. First, an implementation threat can occur when different individuals are assigned to implement different methods, and these individuals differ in ways related to the outcome. To overcome this problem in this study, the teachers who was assigned had the same ability to each group. Second, an implementation threat can occur when some individual have a personal bias in favour of one method over the other [37]. This is the reason why the researcher did not conduct and implement the lesson with a method in this intervention. Teachers who are assigned for the control group were given only the student's edition of the module while, teachers who are assigned for the experimental groups were trained for two weeks on how to use both teacher's and student's edition of the module. The researcher monitored the teaching session by attending the classes for both groups at all schools. Nevertheless, the lesson plan for both experimental and control group were prepared by the researcher together with the other teachers who were conducting the learning sessions in collaboration. These lesson plans were used to ensure that the learning sessions for the students from the different group similar as possible.

\section{Subjects' Attitude}

How subject view a study and participate in it can also threaten internal validity, such as Hawthorne effect [37]. Hawthorne effect can be a problem in educational research [38, 42]. The explanation for this effect is that the special attention and recognition received by the person who was responsible. According to Fraenkel, Wallen, \& Hyun [37], this positive effect, resulting from increased attention and recognition of subjects, has subsequently been referred to as the Hawthorne effect. In this study, the researcher had employed a placebo approach by providing the control groups with similar instructional guidelines and module lessons as what had been given to the experimental groups to ensure that all groups would appear to have been given the same treatment with the hope of reducing the above threats. Students from both groups were given a student's edition of the module. A set of complimentary of a file, stationaries and a module were presented to both groups. It is hope that they did not realize the difference in the subject matter since the covers of the modules were similar. Since, the students in both groups could also interact with one another there was a possibility that the subjects in one group may learn the content intended for others. In this study, mode of instruction differs between both groups, and yet they still focussing on the same four topics that are evaluated in year 5 Mathematics. The only difference was in the HOTS-based module, instructions were given in CA procedures. The control group received the information on the topics through the conventional strategy that emphasized on the 'explain-practice and memorise' method. Meanwhile the experimental group acquired the information through the development and constructions of Measurement and Geometry in conceptual and procedural knowledge using active learning and social learning approach.

\subsubsection{External Validity}

Threats to external validity are problems that threaten our ability to draw correct inferences from the sample data to other 
persons, settings, treatment variables, and measures [41]. Most studies cannot randomly sample from populations of individuals, settings, times, outcomes, and treatment variations because of the expense, time and effort involved as well as the fact that the populations of outcomes and treatment variations are probably not known and cannot, therefore, be adequately sampled [40]. In the context of this study, generalizing is not the intent of this research. It is that, the developed module is suitably designed for a mentioned target group. Hence, the HOTS-based module is specially designed to fit with the subject curriculum and the ministry of education's policy. In this case, this study can only be generalized to year five students in primary schools or in fact the selected population. In addition, the treatment is considered to apply the recommended plan by the formative evaluation.

\subsection{Instrumentation}

In this study, three performance tests (pre-test, post-test and delayed post-test) were applied to measure the students' performance during the treatment. Four sets of questions based on the measurement and geometry topics were planned, designed and developed for the purpose of evaluation of each unit and tested after each of the lessons were complete. The units were length, mass, volume of liquid, and shape and space. The format of each unit was based on HOTs and short-answer questions. Reliability and validity of the developed instruments were determined in the first phase of the pilot study. To measure the interval consistency of the tests, the Cronbach Alpha coefficient was used. According to Fraenkel, Wallen and Hyun [37], the alpha coefficient is a general form of the KR-20 formula that is used to calculate the reliability of items in some essay tests where more than one answer is possible. The schematic coding method is used for formative assessments and learning tests, the scoring methods are confirmed with re-coding by three experts, and lastly the level of reliability is tested. In order to make sure that the questionnaire's item in a single test are consistent among them, internal consistency reliability of the questionnaires is tested through Cronbach's Alpha. Reliability of the tests were 0.74 for pre-test, 0.74 for post-test and 0.75 for post-delayed test. These figures indicated that the instruments were satisfactory for the research purposes. According to Fraenkel et al. [37], many classroom test reports that reliability coefficients of .70 and higher. For research purposes, he stated that a useful rules of thumb is that reliability should be at least .70 and preferably higher. These tests for both groups were conducted three times according to the experimental design. The test paper on the topics of measurement and geometry consisted of 12 subjective questions. As for the HOTS-approach, a module was designed, an expert reviews was conducted as soon as possible after a draft module had been developed. In this study, three expert reviews were chosen, two from the Institute of Teachers Education and one officer (School Improvement Specialist Coaches plus, SISC+) from District Education Office. The validity of the content modules, Likert scale questionnaire was developed and modified based on the questionnaire made from Abdullah and $\mathrm{Za}$ karia [43] study. The evaluation was administered during pilot test and field trial. The evaluation was done first in pilot test in order to improve the module before conducting the next evaluation in the field trial. Using the result from the evaluation in pilot test, the instruction was improved before the final version was implemented in the field trial.

\subsection{Research Procedures}

Prior to the experiment, a pre-test $\left(O_{1}\right)$ was administered to all groups to get the initial difference between experimental and control groups. It determines the homogeneity of the pupils for both groups before treatment. The purpose of the pre-test is to determine whether or not the means of both groups are significantly different, as well as to provide baseline values regarding the variables measured. Therefore, the pre-test was used as covariate in the analysis. The experimental group utilizes the HOTS-based module, while the control group utilizes the conventional approach in the topic of measurement and geometry. After providing the HOTS-based module, posttest $\left(\mathrm{O}_{2}\right)$ was administered to measure the pupils' performance in the topic of measurement and geometry after 12 weeks of the experiment. A delayed post-test $\left(\mathrm{O}_{3}\right)$ was administered two weeks after the post-test was held. Although the term delayed effect is used to refer to the effect of treatment seen after a period of time, in the context of the study, the delayed effect, means remembering and internalizing what pupils have learned about HOTS during the treatment sessions. No additional treatment or feedback provided after the post-test and prior to delay post-test. In the process of instruction, different teachers handle the experimental group and control group. This situation cannot be avoided since the teacher has been assigned to a particular class by the schools' administer. Figure 5 demonstrates the experimental procedure of this study. At the beginning of the study, the teacher gave a short briefing to the pupils regarding the intervention instructional procedures. The learning strategy based on Cognitive Apprenticeship Model (CAM) played an important role in facilitating pupils' involvement in the HOTS-approach. After a pre-test was given to both groups, the teacher started adopting the HOTS approach for the experimental group and conventional approach for the control group.

\section{Results}

Table 1 shows the percentage of different types of errors between urban and rural location pupils in solving four word problems of measurement and geometry. The total percentage of errors rural pupils made was more than that made by urban pupils. Pupils in treatment group of school1 from urban location made E1 (18.2\%) errors more than other schools, whereas pupils in control group of school2 did not make any E1 errors. Pupils in control group of school 2 from urban location made E2 $(30.0 \%)$ errors more than other schools. Whereas, pupils in both groups from urban and rural location made E3 errors were quite same in percentages. Pupils in control group of school4 from rural location made E4 $(39.3 \%)$ errors more than pupils from urban schools. Pupils in control group of schooll from 
urban location made E5 (30.0\%) errors, which was no solution or leaving blank more than other schools. The result in Table 1 indicated that pupils in the treatment group made less errors (urban: 65.2\% and rural: $90.4 \%$ ) compared to pupils in control group (urban: $77.5 \%$ and rural: $94.4 \%$ ) in both locations. This result also showed that pupils from urban schools (76.9\%) less errors compared to pupils in rural schools $(92.4 \%)$.

Table 2 shows that there was only one pupil in control group of school4 that made E1 error for problem8. Most of the schools' pupils in both locations made E2 errors for problem8. In problem9, all pupils from both locations made errors of E1 to E5. Only two pupils made E2 errors, whereas 17 pupils made E4 errors. Pupils from rural schools made more errors compared to pupils from urban school. Most pupils in treatment group made less errors compared to pupils in control group in problem9, except pupils from schools. For problem11, most of the pupils from urban and rural schools made E3 and E4 errors. Pupils from rural schools made less E1 and E2 errors compared to pupils from urban schools. However pupils from rural schools made more E3 and E4 errors compared to pupils from urban schools. The number of pupils from treatment groups and control groups who made errors in problem11 is almost the same. Pupils from both locations made no errors of E1 for problem12. However, most pupils from both locations made E4 errors. The number of errors made by both groups (treatment and control) in both location are almost the same. The result indicated that most pupils made errors for problem12. Problem11 was the second question that most pupils made errors. Pupils from rural schools made more errors compared to pupils in urban schools in Problem8, Problem 11 and Problem12. However both pupils in urban and rural schools made same number of errors in Problem9.

\subsection{Examples of errors made by pupils from both loca- tions after the Intervention}

In Problem8, among the pupils in treatment groups who made E2 errors, $22.5 \%$ of the urban and 35\% of the rural pupils present half of the correct steps in the solution. Whereas, pupils in control groups who presented E2 errors, came from $20.5 \%$ of the urban and $33.3 \%$ of the rural pupils. There were no actual error is made than incomplete effort of a schema that leading to a correct solution. Most of the pupils produced the first step of the word problem that is the length of the exercise book is five times the length of the eraser $(5 \mathrm{~cm} \times 5=25 \mathrm{~cm})$. At this stage, there were no second level errors committed. About $2.5 \%$ of urban and $2.5 \%$ rural pupils in the treatment group respectively made E3 errors, whereas none of pupils in the control group from both location made E3 errors. Pupils in treatment group from each location commit an error which indicates inability to connect relevant schemata. At this stage, the second level error was made in the comprehension and mathematical theme categories because the pupil could understand the word " $4 \mathrm{~cm}$ more".

About $2.5 \%$ of the pupils in the treatment group from urban school and 5.0\% from rural school made E4 errors. While, none of the pupils in the control group from urban school and $5.1 \%$ of the pupils in the control group from rural school made
E4 errors. At this point, pupils were unable to connect or make a link between the chosen solution and the question given. For example the pupil could not understand the word " 5 times the length of the eraser" and " $4 \mathrm{~cm}$ more". About $7.5 \%$ of the pupils in the treatment group from urban school and 2.5\% from rural school made E5 errors. While, $7.7 \%$ of the pupils in the control group from urban school and 2.6\% from rural school made E5 errors. At this point, pupils were unable to relate their schema to the information obtained from the question. The example given above indicates that the pupils were unable to retrieve relevant information to apply in the solution.

Problem8: Kamala measure an exercise book using an eraser with the length of $5 \mathrm{~cm}$. The length of the exercise book is $4 \mathrm{~cm}$ more than 5 times the length of the eraser. What is the length of the exercise book?

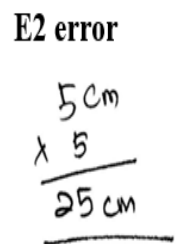

E3 error
E4 error.

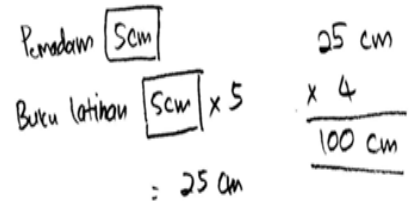

E5 error

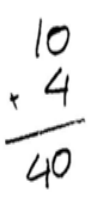

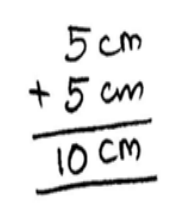

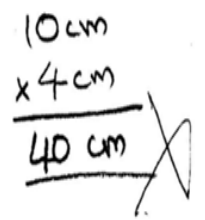

Figure 6. Different types of errors solving in Problem8.

In Problem9, among the pupils in the treatment group making E1 errors, $12.5 \%$ of the urban and 5\% of the rural pupils present the solution with an error in computation or encoding of information. Whereas, the pupils in the control group making E1 errors, were $2.6 \%$ of the urban and $12.8 \%$ of the rural pupils. In the example, pupil made careless mistake in subtraction by decomposition. In this solution, the second level error was operational, which is in computation. About $2.5 \%$ of rural pupils in the treatment group making E2 errors, none of the urban pupils made E2 error. However, none of rural pupils in the control group making E2 errors, and $2.6 \%$ of the urban pupils made E2 error. As we can see, there is no actual error made than incomplete work of a schema that leading to a correct solution. At this stage, there were no second level errors committed. Only $7.5 \%$ of urban pupils in the treatment group, whereas none of rural pupils made E3 errors. About $7.7 \%$ of the pupils in control groups from both location presented E3 errors. From the example, the pupil completed the first step solution, but unable to perform the second step solution. At this stage, the second level error was made in the comprehension and mathematical theme categories because the pupil could understand the word "adds again $398 \mathrm{ml}$ of water".

About $2.5 \%$ of the pupils in the treatment group from ur- 
Table 1. The percentage of different types of errors between urban and rural location pupils in solving four word problems of measurement and geometry

\begin{tabular}{|c|c|c|c|c|c|c|c|c|}
\hline Type of Error & \multicolumn{4}{|c|}{ Urban } & \multicolumn{4}{|c|}{ Rural } \\
\hline & \multicolumn{2}{|c|}{ school1 } & \multicolumn{2}{|c|}{ school2 } & \multicolumn{2}{|c|}{ school3 } & \multicolumn{2}{|c|}{ schooll } \\
\hline & treatm & control & treatm & control & treatmer & control & treatmen & control \\
\hline E1 & 18.2 & 2.5 & 2.1 & 0 & 4.5 & 6.3 & 3.1 & 10.7 \\
\hline E2 & 13.6 & 17.5 & 12.5 & 30 & 20.5 & 22.9 & 25 & 14.3 \\
\hline E3 & 20.5 & 12.5 & 14.6 & 22.5 & 22.7 & 20.8 & 15.6 & 17.9 \\
\hline E4 & 9.1 & 30 & 10.4 & 5 & 31.8 & 41.7 & 31.3 & 39.3 \\
\hline E5 & 2.3 & 30 & 27.1 & 5 & 13.6 & 4.2 & 12.5 & 10.7 \\
\hline $\begin{array}{l}\text { Total percentage } \\
\text { (group) }\end{array}$ & 63.6 & 92.5 & 66.7 & 62.5 & 93.2 & 95.8 & 87.5 & 92.9 \\
\hline $\begin{array}{l}\text { Mean percentage } \\
\text { (location) }\end{array}$ & \multicolumn{2}{|c|}{$\begin{array}{l}\text { Treatment } \\
\quad 65.2\end{array}$} & \multicolumn{2}{|c|}{$\begin{array}{c}\text { Control } \\
77.5\end{array}$} & \multicolumn{2}{|c|}{$\begin{array}{c}\text { Treatment } \\
90.4\end{array}$} & \multicolumn{2}{|c|}{$\begin{array}{c}\text { Control } \\
94.4\end{array}$} \\
\hline
\end{tabular}

Note: E1 = Complete schema with errors; E2 = Incomplete schema with no errors; E3 = Incomplete schema with errors; E1 = Using irrelevant procedures; E5 = No solution.

Table 2. Number of pupils between urban and rural location making different types of errors in solving four word problems of measurement and geometry.

\begin{tabular}{|c|c|c|c|c|c|c|c|c|}
\hline Problems & Location & School & Group & E1 & E2 & E3 & E4 & E5 \\
\hline \multirow[t]{8}{*}{ Problem8 } & \multirow[t]{4}{*}{ Urban } & \multirow[t]{2}{*}{ School1 } & Treatment & 0 & 5 & 1 & 0 & 0 \\
\hline & & & Control & 0 & 6 & 0 & 0 & 3 \\
\hline & & \multirow[t]{2}{*}{ School2 } & Treatment & 0 & 4 & 0 & 1 & 3 \\
\hline & & & Control & 0 & 2 & 0 & 0 & 0 \\
\hline & \multirow[t]{4}{*}{ Rural } & \multirow[t]{2}{*}{ School3 } & Treatment & 0 & 6 & 1 & 2 & 1 \\
\hline & & & Control & 0 & 9 & 0 & 2 & 0 \\
\hline & & \multirow[t]{2}{*}{ School4 } & Treatment & 0 & 8 & 0 & 0 & 0 \\
\hline & & & Control & 1 & 4 & 0 & 0 & 1 \\
\hline \multirow[t]{8}{*}{ Problem9 } & \multirow[t]{4}{*}{ Urban } & \multirow[t]{2}{*}{ School1 } & Treatment & 4 & 0 & 0 & 0 & 0 \\
\hline & & & Control & 1 & 0 & 3 & 1 & 3 \\
\hline & & \multirow[t]{2}{*}{ School2 } & Treatment & 1 & 0 & 3 & 1 & 2 \\
\hline & & & Control & 0 & 1 & 0 & 0 & 0 \\
\hline & \multirow[t]{4}{*}{ Rural } & \multirow[t]{2}{*}{ School3 } & Treatment & 1 & 1 & 0 & 4 & 1 \\
\hline & & & Control & 3 & 0 & 3 & 5 & 0 \\
\hline & & \multirow[t]{2}{*}{ School4 } & Treatment & 1 & 0 & 0 & 3 & 0 \\
\hline & & & Control & 2 & 0 & 0 & 3 & 1 \\
\hline \multirow[t]{8}{*}{ Problem11 } & \multirow[t]{4}{*}{ Urban } & \multirow[t]{2}{*}{ School1 } & Treatment & 4 & 1 & 2 & 1 & 0 \\
\hline & & & Control & 0 & 1 & 2 & 4 & 3 \\
\hline & & \multirow[t]{2}{*}{ School2 } & Treatment & 0 & 1 & 4 & 0 & 3 \\
\hline & & & Control & 0 & 0 & 8 & 2 & 0 \\
\hline & \multirow[t]{4}{*}{ Rural } & \multirow[t]{2}{*}{ School3 } & Treatment & 1 & 0 & 8 & 2 & 1 \\
\hline & & & Control & 0 & 1 & 6 & 5 & 0 \\
\hline & & \multirow[t]{2}{*}{ School4 } & Treatment & 0 & 0 & 5 & 2 & 1 \\
\hline & & & Control & 0 & 0 & 3 & 4 & 0 \\
\hline \multirow[t]{8}{*}{ Problem12 } & \multirow[t]{4}{*}{ Urban } & \multirow[t]{2}{*}{ School1 } & Treatment & 0 & 0 & 6 & 3 & 1 \\
\hline & & & Control & 0 & 0 & 0 & 7 & 3 \\
\hline & & \multirow[t]{2}{*}{ School2 } & Treatment & 0 & 1 & 0 & 3 & 5 \\
\hline & & & Control & 0 & 9 & 1 & 0 & 0 \\
\hline & \multirow[t]{4}{*}{ Rural } & \multirow[t]{2}{*}{ School3 } & Treatment & 0 & 2 & 1 & 6 & 3 \\
\hline & & & Control & 0 & 1 & 1 & 8 & 2 \\
\hline & & \multirow[t]{2}{*}{ School4 } & Treatment & 0 & 0 & 0 & 5 & 3 \\
\hline & & & Control & 0 & 0 & 2 & 4 & 1 \\
\hline
\end{tabular}

ban school and $17.5 \%$ of the pupils from rural school made E4 errors. While, $2.6 \%$ of the pupils in the control group from urban school and $20.5 \%$ of the pupils from rural school made E4 errors. The example indicates that the pupils were unable to retrieve relevant information to apply in the solution. In this solution, the second level error was in comprehension and mathematical theme categories. About $5.0 \%$ of the pupils in the treatment group from urban school and $2.5 \%$ of the pupils from rural school made E5 errors. While $7.7 \%$ of the pupils in the control group from urban school and $2.6 \%$ of the pupils from rural school made E5 errors. According to Fong (1995) [28], this category refers to a solution with no written response.

Problem9: The capacity of a pot is $2,419 \mathrm{ml}$ of water. Yusof fills $11299 \mathrm{ml}$ of water into the empty pot. Then, he adds again
$398 \mathrm{ml}$ of water. How much more water can be filled into that pot? Yusof fills $11299 \mathrm{ml}$ of water into the empty pot. Then, he adds again $398 \mathrm{ml}$ of water. How much more water can be filled into that pot?

In Problem11, among the pupils in the treatment groups presented the E1 errors, were $10.0 \%$ of the urban and $2.5 \%$ of the rural pupils, while none of the pupils in the control groups presented the E1 errors, showed the solution with an error in computation or encoding of information. In the example, pupil made mistake in the operation of multiplying whole number with decimal. Pupils were confused when they wrote 11 as 11.0, and multiplied it with a decimal number of 5.5. In this solution, the second level error was operational, which is in computation. Only $5.0 \%$ of rural pupils in the treatment groups 


\section{E1 error.}

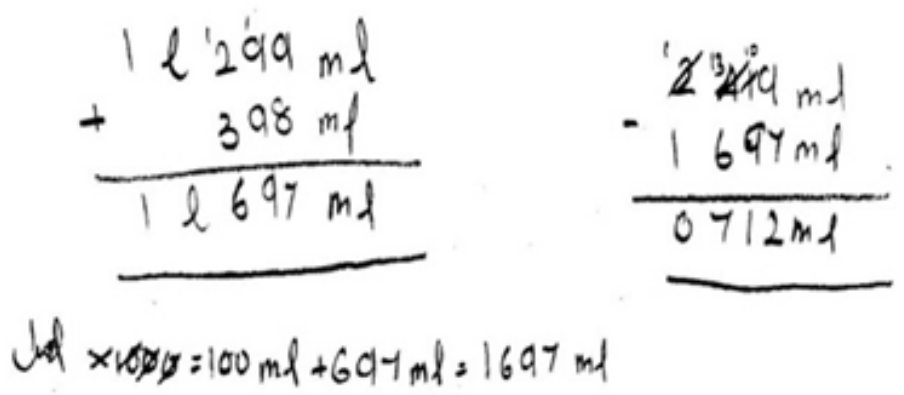

E3 error

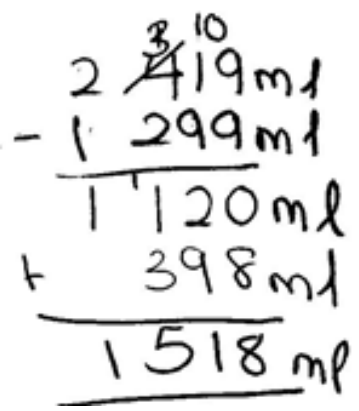

E2 error

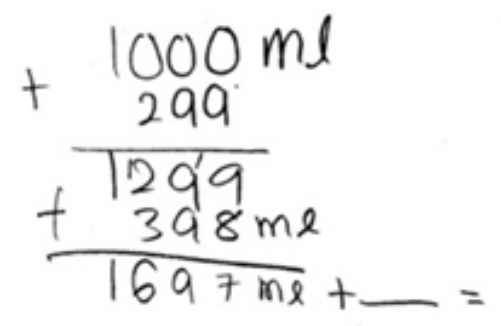

E4 error

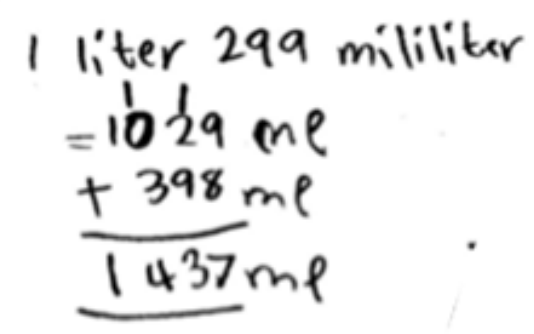

Figure 7. Different types of errors solving in Problem9

making E2 errors, none of the urban pupils made E2 error, while $2.6 \%$ of pupils in control groups from both location making E2 errors. As we can see, there is no actual error made than incomplete work of a schema that leading to a correct solution. At this stage, there were no second level errors committed. About $15.0 \%$ of urban pupils, whereas $32.5 \%$ of rural pupils in the treatment groups made E3 errors, while $25.6 \%$ of urban pupils, whereas $23.1 \%$ of rural pupils in control groups made E3 errors. From the example, the pupil completed the first step solution, but unable to perform the second step solution. At this stage, the second level error was made in the comprehension and mathematical theme categories because the pupil could understand the word "area of the red paper that will appear". Nearly $2.5 \%$ of the pupils in the treatment groups from urban school and $10.0 \%$ of the pupils from rural school made E4 errors, whereas $15.4 \%$ of the pupils in the control groups from urban school and $23.1 \%$ of the pupils from rural school made E4 errors. The example indicates that the pupils were unable to retrieve relevant information to apply in the solution. In this solution, the second level error was in comprehension and mathematical theme categories.

About $7.5 \%$ of the pupils in the treatment group from urban school and $5.0 \%$ of the pupils from rural school made E5 errors, while $7.7 \%$ of the pupils in the control group from urban school and none of the pupils from rural school made E5 errors. According to Fong (1995) [28], this category refers to a solution with no written response. In this solution, the pupil is incapable to make a connection between his existing schema and the information acquired from the problem.

Problem11: Qaisarah has a piece of red paper with $5.5 \mathrm{~cm}$ wide. The length of red paper is twice its width. Qaisarah paste the blue paper measuring $4.5 \mathrm{~cm}$ by $7 \mathrm{~cm}$ on the red paper. What is the area of the red paper that will appear? 


\section{E1 error}

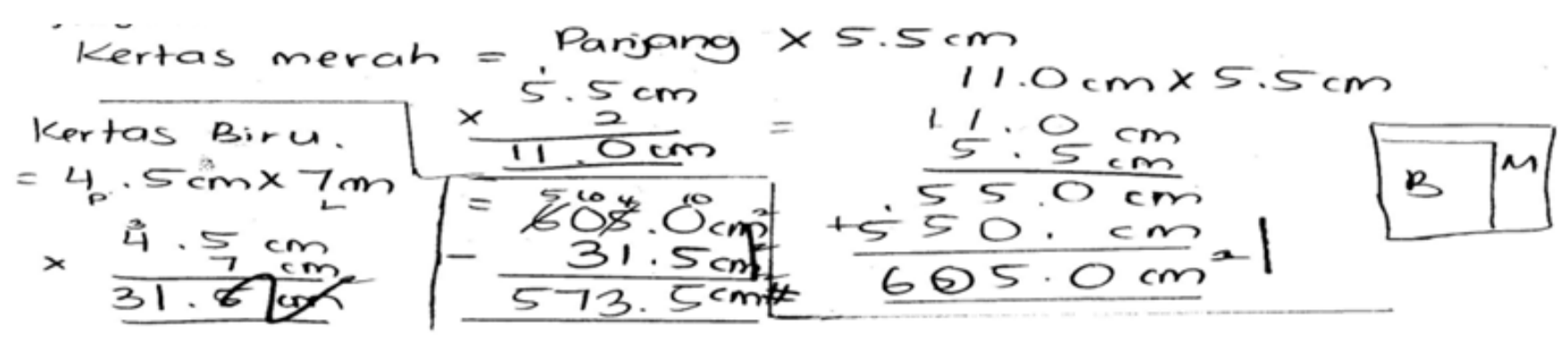

\section{E2 error}

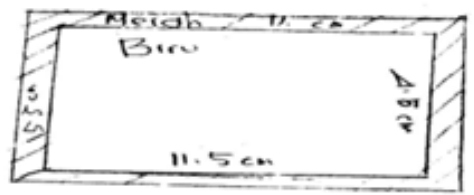

E3 error

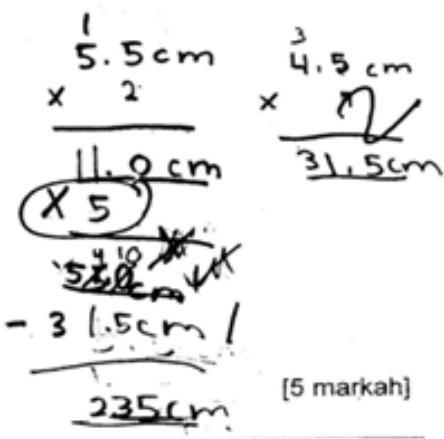

$$
\begin{aligned}
& 5.5 \mathrm{~cm} \\
& -\frac{555}{11505} \\
& \hline 605
\end{aligned}
$$

E4 error

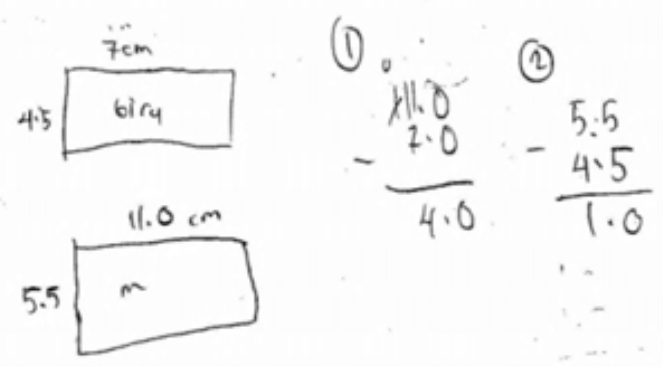

(3) $4: 0$

$$
+\frac{1.0}{5.0 \mathrm{~cm}}
$$

Figure 8. Different types of errors solving in Problem11 
In Problem12, pupils from both groups and both location have none error of E1. For the E2 errors, $2.5 \%$ of the urban and $5.0 \%$ of the rural pupils in the treatment groups present half of the correct steps in the solution, while $23.1 \%$ of the urban and $2.6 \%$ of the rural pupils in the control groups made the E2 errors. There were no actual error is made than incomplete effort of a schema that leading to a correct solution. Most of the pupils produced the first step of the word problem that is subtracting the total mass of four pineapples and three oranges with the total mass of three pineapples and two oranges to get the total mass of one pineapple and one orange. At this stage, there were no second level errors committed. About $15.0 \%$ of urban and $2.5 \%$ rural pupils in the treatment groups respectively made E3 errors. Pupils from each location commit an error which indicates inability to connect relevant schemata. However, $2.6 \%$ of urban and $7.7 \%$ of rural pupils in the control groups made E3 errors.

At this stage, the second level error was made in the comprehension and mathematical theme categories. From the example, we can see that the pupil understand that "Each pineapple have the same mass, so is the mass of each oranges" means that both a pineapple and an orange have the same mass, hence the pupil perform a division of $5.0 \mathrm{~kg}$ in mass. $15.0 \%$ of the pupils in the treatment group from urban school and $27.5 \%$ of the pupils from rural school made E4 errors, while $17.9 \%$ of the pupils in the control group from urban school and $30.8 \%$ of the pupils from rural school made E4 errors. The example indicate that the pupil add up the number of both fruits (four pineapples and three oranges equal to seven fruits and, three pineapples and two oranges equal to five fruits). The pupil then divides the total mass of both fruits with the total number of the fruits. The solution shows that the pupils were unable to retrieve relevant information to apply in the solution. About $15.0 \%$ of the pupils in the treatment groups from both location and $7.7 \%$ of the pupils in the control groups from both locations made E5 errors.

Problem12: A mass of 3 pineapples and 2 oranges are $14.5 \mathrm{~kg}$, while the mass of 4 pineapples and 3 oranges are $19.5 \mathrm{~kg}$. Each pineapple has the same mass, so is the mass of each orange. What is the mass of a pineapple and a lemon?

\section{Discussions}

As mention previously, pupils in treatment groups in both locations (School1; School2; School3; School4) made less errors compare to pupils in control group. This result indicated that pupils who used HOTS-based module committed less errors in solving measurement and geometry problems. By utilizing HOTS-based module, pupils were exposed to a variety of problem solving strategies, one of them was visual representations (bar diagram). According to Rittle-Johnson and Koedinger [44], visual representations might allow pupils to reason through how to solve the problem and reject answer that were not conceptually possible. By drawing the bar diagram, pupil can see clearly how to calculate and solve the problem. This action also avoid pupil in making errors. In this study, this showed that although pupils' errors were often due to misconceptions, the teacher need to be aware that pupils can and do made careless errors. This type of errors may occur because pupils were competitive and rush in their work to finish it $[16,45]$ stated that pupils who frequently experience involvement of concentration in mathematics, displayed carelessness. On the other hand, Clement [23] stated that there was a positive relationship between carelessness and confidence, such that pupils who understand the content and believed that they can answer the problem, made higher percentage in careless errors. Therefore, pupils with average knowledge may have tendencies to misjudge their own ability [46]. Similarly, pupils who had less motivation may not able to concentrate and so made careless or computational errors. Pupils who have difficulties in giving attention could not concentrate on a particular task in a longer time [47]. Moreover, to give concentration in certain duration of time, pupils have to strength their intrinsic motivation.

Based on Table 1, the data indicated that pupils from rural schools had higher percentage to commit in E2 and E4 errors. In the E2 (incomplete schema with no errors) error, pupils showed some of the correct steps in the solution without committed any error. This situation showed that pupils from rural schools could not make a connection among the relevant information which leads to the solution. According to Cheng [48], most pupils could perform 1-step word problems, but not all could transit 1-step to 2-step word problems. She stated that this situation stressed on the significance of accurate scaffolding for pupils during transiting from 1-step to 2-step word problems. Moreover, the errors that pupils developed during earlier classes or brought them to school from outside environment can generate interferences in the current learning of mathematical concepts; hence bring into the poor achievement in mathematics [49]. If the teacher is conscious of the pre-requisites knowledge for 1-step addition and subtraction, maybe then, the teacher could design lesson plan for 2-step word problems that matched to the learning needs of the pupils [48]. However, pupils from both locations committed the E3 errors nearly at the same percentage. This result indicated that they failed to demonstrate correct computation and ability to connect all the significant schemas, especially in Problem11. Misconceptions in understanding the main idea of the problem cause them to make errors. The pupils com- 


\section{E2 error}

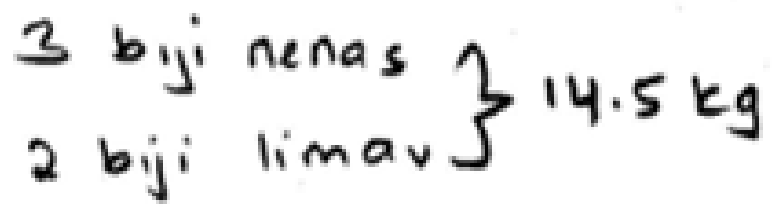

4biji nenas

3 biji limav $\{19.5 \mathrm{~kg}$

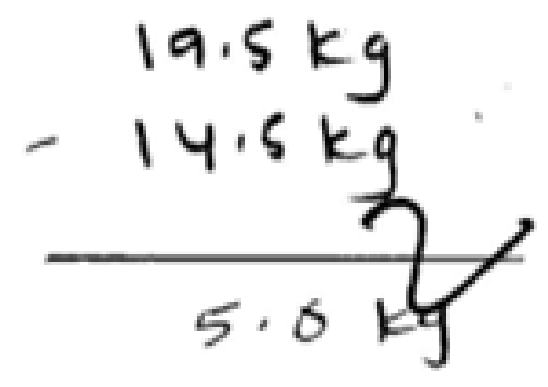

\section{E3 error}

$$
\begin{aligned}
& \underbrace{0 \mathrm{KO}^{\circ}}_{14.5 \mathrm{Kg}}
\end{aligned}
$$

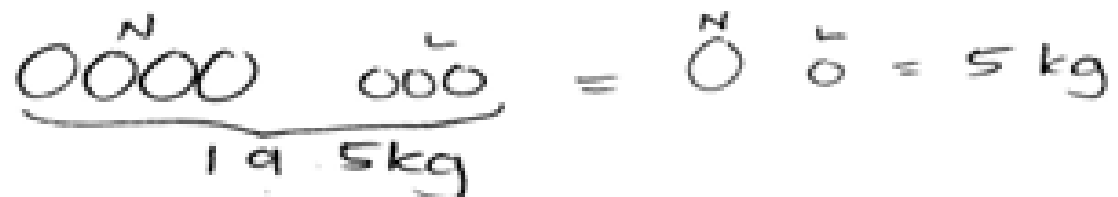

$$
\begin{aligned}
& \begin{array}{r}
19.5 \mathrm{~kg} \\
-14.5 \mathrm{~kg} \\
\hline \\
\hline
\end{array} \\
& =\frac{1 \frac{2}{5} \cdot 0 \mathrm{~kg}}{1.0} \\
& \frac{10}{00}
\end{aligned}
$$

\section{E4 error}

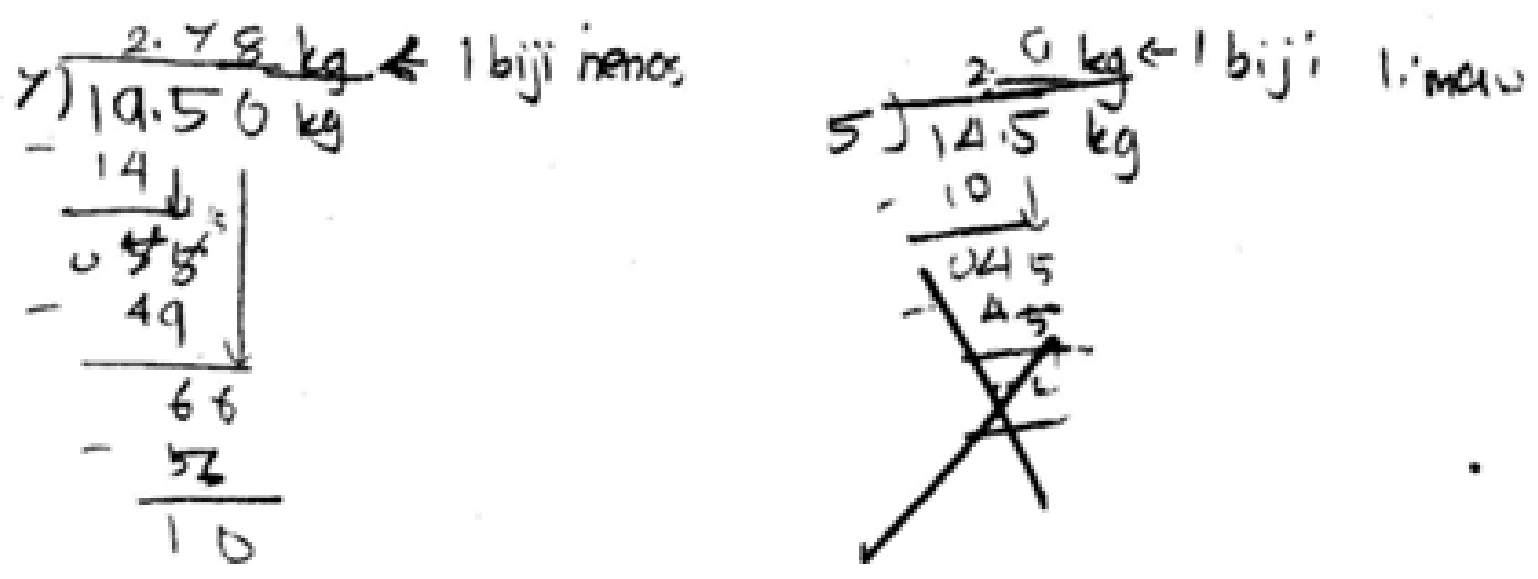

Figure 9. Different types of errors solving in Problem12. 
pleted the first step solution, but unable to perform the second step solution. At this stage, the second level error was made in the comprehension and mathematical theme categories because the pupil could understand the word "area of the red paper that will appear". In this situation, partially incorrect answer gave the understanding into content or skills that the pupils could developed.

According to Herholdt and Sapire [30], partially correct answers indicated that the pupils were aware of the correct operation that needed to be done, but did not complete the operation correctly. This indicates some conceptual understanding, even though there were procedural errors made in the solutions. Errors involved both conceptual and procedural understandings were seen as a natural part of the learning process [50]. Pupils from rural school who committed E4 (use irrelevant procedures) errors indicate that they were lack of understanding of the content in the particular item. According to Maf'ulah, Juniati \& Siswono [34], pupil who performed this type of errors failed to identify the unknown to be evaluated. This error also could be due to incorrect interpretation of the problem situation or a situation when the misinterpretation part of the problem situation [51].

\section{Conclusion}

In this paper, errors and misconceptions made by year five pupils were analyzed and categorized using the Fong's schematic model. Results from tests showed that pupils who were exposed to HOTS approach made less errors compared to pupils who were in the conventional groups. In terms of location, this study has proven that pupils in urban areas had committed fewer errors than their rural counterpart. In other words, pupils in urban schools have a very great advantage by learning in an urban environment, which actually enriches their academic knowledge as well as their HOTS. Pupils in urban schools get best opportunities provided by their location, such as greater access to many resources and opportunities that are not accessible to rural pupils. It is recommended that the rural teachers should diversify their teaching strategies and methods in the Measurement and Geometry topic. Motivation diversity should be emphasized to their pupils. Teachers should always think of the best remedial activities with instant effect to overcome the difficulty of understanding among their pupils.

\section{REFERENCES}

[1] J. Huang. Applying higher-order thinking in E-learning design, Proceedings from ICHL'11: Fourth International Conference on Hybrid Learning, Springer, Berlin, 135 - 145, 2011.

[2] L. E. Richland, N. Simms. Analogy, higher order thinking, and education, Wiley Interdisciplinary Reviews: Cognitive Science, Vol.6, No.2, 177-192, 2015.
[3] A. Thomas, G. Thorne. How to increase higher order thinking. Metarie, LA: Center for Development and Learning, Retrieved from http://www.readingrockets.org/article/how-increasehigher-order-thinking?theme=print, 2009.

[4] S. M. Brookhart. How to assess higher-order thinking skills in your classroom, ASCD, Virginia, 2010.

[5] B. S. Bloom. Taxonomy of educational objectives, Handbook I: The cognitive domain, McKay, New York, 1956.

[6] W. Huitt. Bloom's taxonomy of the cognitive domain, Educational Psychology Interactive, Valdosta, GA: Valdosta State University, Retrieved from http://www.edpsycinter active.org/topics/cogsys/bloom.html, 2011.

[7] L. W. Anderson, D. R. Krathwohl, B. S. Bloom. A taxonomy for learning, teaching, and assessing: A revision of Bloom's taxonomy of educational objectives, Allyn \& Bacon, Boston, 2001.

[8] T. Sulaiman, A. F. M. Ayub, S. Sulaiman. Curriculum Change in English Language Curriculum Advocates Higher Order Thinking Skills and Standards-Based Assessments in Malaysian Primary Schools, Mediterranean Journal of Social Sciences, Vol.6, No.2, 494-500, 2015.

[9] E. Surya, E. Syahputra. Improving High-Level Thinking Skills by Development of Learning PBL Approach on the Learning Mathematics for Senior High School Students, International Education Studies, Vol.10, No.8, 12-20, 2017.

[10] L. S. Leung. An inquiry of teachers' perception on the relationship between higher-order thinking nurturing and public assessment in Hong Kong, Hong Kong Teachers' Centre Journal, Vol.12, 183-215, 2013.

[11] J. Pegg. Promoting the acquisition of higher order skills and understandings in primary and secondary mathematics, In Research Forum 2010, Retrieved from https://research. acer.edu.au/cgi/viewcontent.cgi?referer=https : //scholar.google.com/\&httpsredir=1\&article=1081\& context=research_conference 36-38, 2010.

[12] Ministry of Education Malaysia. Dokumen Standard Kurikulum dan Pentaksiran KSSR Matematik Tahun 5, Curriculum Development Centre, Kuala Lumpur, 2014.

[13] A. M. Johar, E. Zakaria. Analisis kesilapan bagi tajuk pecahan dalam kalangan murid tahun empat (Error analysis of fraction among year four pupils), Jurnal Pendidikan Matematik, Vol.3, No.2, 1-17, 2015.

[14] H. Radatz. Students' errors in the mathematical learning process: a survey, For the learning of Mathematics, Vol.1, No.1, 16-20, 1980. 
[15] P. J. Riccomini. Identification and remediation of systematic error patterns in subtraction, Learning Disability Quarterly, Vol.28, No.3, 233-242, 2005.

[16] A. Hansen, D. Drews, J. Dudgeon, F. Lawton, L. Surtees. Children's errors in mathematics, On the State of Computing in Statistics Education: Tools for Learning and for Doing, Learning Matters, Glasgow, 2005.

[17] G. H. Roberts. The failure strategies of third grade arithmetic pupils, Arithmetic Teacher, Vol.15, 142-146, 1968.

[18] J. M. Engelhardt. Analysis of children's computational errors: A qualitative approach, British Journal of Educational Psychology, Vol.47, No.2, 149-154, 1977.

[19] P. A. Spiers. Acalculia revisited: current issues, In G. Deloche and X. Seron (Eds), Mathematical disabilities, A cognitive neuropsychological perspective, LEA, London, 1987.

[20] L. L. Morin, S. M. Watson, P. Hester, S. Raver. The Use of a Bar Model Drawing to Teach Word Problem Solving to Students With Mathematics Difficulties, Learning Disability Quarterly, Vol.40, No.2, 91-104, 2017.

[21] C. Hord, Y. P. Xin. Teaching area and volume to students with mild intellectual disabilities, The Journal of Special Education, Vol.49, No.2, 118-128, 2015.

[22] M. A. Newman: An analysis of sixth-grade pupils' errors on written mathematical tasks, Victorian Institute for Educational Research Bulletin, Vol.39, 31-43, 1977.

[23] M. A. Clements. Careless errors made by sixth-grade children on written mathematical tasks, Journal for Research in Mathematics Education, Vol.13, No.2, 136-144, 1982.

[24] P. C. Clarkson. The Newman error analysis-Some extensions, Research in mathematics education in Australia, Vol.1,11-22, 1980.

[25] I. Watson. Investigating errors of beginning mathematicians, Educational Studies in Mathematics, Vol.11, No.3, 1980.

[26] C. Jiang. Errors in solving word problems about speed: A case in Singapore and Mainland China, New Waves, Vol.16, No.1, 56-75, 2013.

[27] H. Radatz. Error analysis in mathematics education, Journal for Research in Mathematics Education, 163-172, 1979.

[28] H. K. Fong. Schematic Model for Categorising Children's Errors in Solving a Ratio and Proportion Problem, Hiroshima Journal of Mathematics Education, Vol.3, 15-29, 1995.
[29] A. L. White. Active mathematics in classrooms: finding out why children make mistakes-and then doing something to help them, Square one, Vol.15, No.4, 15-19, 2005.

[30] R. Herholdt, I. Sapire. An error analysis in the early grades mathematics-A learning opportunity?, South African Journal of Childhood Education, Vol.4, No.1, 43-60, 2014.

[31] C. Bastien, M. Bastien-Toniazzo. Apprendre à l'école, Armand Colin, Paris, 2004.

[32] P. L. Ayres. Systematic mathematical errors and cognitive load, Contemporary Educational Psychology, Vol.26, No.2, 227-248, 2001.

[33] S. M. Ravizza, J. R. Anderson, C. S. Carter. Errors of mathematical processing: The relationship of accuracy to neural regions associated with retrieval or representation of the problem state, Brain Research, Vol.1238, 118-126, 2008.

[34] S. Maf'ulah, D. Juniati, T. Y. E. Siswono. Pupils' error on the concept of reversibility in solving arithmetic problems, Educational Research and Reviews, Vol.11, No.18, 1775, 2016.

[35] Z. Salleh, N. M. Saad, M. N. Arshad, H. Yunus, E. Zakaria. Analisis Jenis Kesilapan Dalam Operasi Penambahan Dan Penolakan Pecahan (Error Analysis of Addition and Subtraction of Fractions), Jurnal Pendidikan Matematik, Vol.1, No.1, 1-10, 2013.

[36] A. C. Klassen, J. Creswell, V. L. P. Clark, K. C. Smith, H. I. Meissner. Best practices in mixed methods for quality of life research, Quality of Life Research, Vol.21, No.3, 377-380, 2012.

[37] J. R. Fraenkel, N. E. Wallen, H. H. Hyun. Internal validity, How to Design and Evaluate Research in Education, McGraw-Hill, New York, 2012.

[38] D. Ary, L. C. Jacobs, C. K. Sorensen, D. Walker. Introduction to research in education. Wadsworth Cengage Learning, Belmont, CA, 2013.

[39] F. Apaloo. Comparing Performance of Propensity Scores Techniques and Ordinary Least Square Methods in Estimating Treatment Effects: A Monte Carlo Simulation Study, Retrieved from https://web.kamihq.com/web/viewer.html? source=extension_pdfhandler\&file=https $\% 3 \mathrm{~A} \% 2 \mathrm{~F} \%$ 2Ffiles.eric.ed.gov\%2Ffulltext $\% 2$ FED565165.pdf 2013.

[40] L. B. Christensen, B. Johnson, L. A. Turne. Research methods, design, and analysis, 2010. 
[41] J. W. Creswell. A concise introduction to mixed methods research, Sage Publications, Thousand Oaks, United States, 2014.

[42] L. R. Gay, G. Mills, P. W. Airasian. Educational research: Competencies for analysis and interpretation, Merrill PrenticeHall, Upper Saddle Back, NJ, 2009.

[43] A. H. Abdullah, E. Zakaria. Students' perceptions towards the Van Hiele's phases of learning geometry using Geometer's Sketchpad software, Australian Journal of Basic and Applied Sciences, Vol.5, No.7, 787-792, 2011.

[44] B. Rittle-Johnson, K. R. Koedinger. Designing knowledge scaffolds to support mathematical problem solving, Cognition and Instruction, Vol.23, No.3, 313-349, 2005.

[45] M. O. Z. San Pedro, R. S. d Baker, M. M. T. Rodrigo. Carelessness and affect in an intelligent tutoring system for mathematics, International Journal of Artificial Intelligence in Education, Vol.24, No.2, 189-210, 2014.

[46] E. A. Linnenbrink, P. R. Pintrich. The role of self-efficacy beliefs instudent engagement and learning in the classroom, Reading \& Writing Quarterly, Vol.19, No.2, 119-137, 2003.
[47] T. Tambychik, T. S. M. Meerah. Students' difficulties in mathematics problem-solving: What do they say?, Procedia-Social and Behavioral Sciences, Vol.8, 142-151, 2010.

[48] L. P. Cheng. Error Analysis for Arithmetic Word Problems-A Case Study of Primary Three Students in One Singapore School, International Journal for Mathematics Teaching and Learning, Retrieved from http://www.cimt.org.uk/journal/lupien.pdf, 456-483, 2015.

[49] R. G. Mohyuddin, U. Khalil. Misconceptions of students in learning mathematics at primary level, Bulletin of Education and Research, Vol.38, No.1, 133-162, 2016.

[50] P. Nesher. Towards an instructional theory: The role of student's misconceptions, For the learning of mathematics, Vol.7, No.3, 33-40, 1987.

[51] S. F. Ng, K. Lee. The model method: Singapore children's tool for representing and solving algebraic word problems, Journal for Research in Mathematics Education, 282-313, 2009. 